\title{
Evaluation of 6 candidate genes on chromosome 11 q23 for coeliac disease susceptibility: a case control study
}

\author{
Karen Brophy ${ }^{+1,2}$, Anthony W Ryan*11,2, Graham Turner1,2, Valerie Trimble1,2, Kunal D Patel1,2, Colm O'Morain4, \\ Nicholas P Kennedy ${ }^{1}$ Brian Egan4, Eimear Close5, Garrett Lawlor ${ }^{5}$, Padraic MacMathuna5, Fiona M Stevens ${ }^{6}$, \\ Mohamed Abuzakouk 3,7, Conleth Feighery2,3, Dermot Kelleher1,2 and Ross McManus 1,2
}

\begin{abstract}
Background: Recent whole genome analysis and follow-up studies have identified many new risk variants for coeliac disease (CD, gluten intolerance). The majority of newly associated regions encode candidate genes with a clear functional role in T-cell regulation. Furthermore, the newly discovered risk loci, together with the well established HLA locus, account for less than $50 \%$ of the heritability of CD, suggesting that numerous additional loci remain undiscovered. Linkage studies have identified some well-replicated risk regions, most notably chromosome 5q31 and $11 \mathrm{q} 23$.

Methods: We have evaluated six candidate genes in one of these regions (11q23), namely CD3E, CD3D, CD3G, IL10RA, THY1 and IL18, as risk factors for CD using a 2-phase candidate gene approach directed at chromosome 11 q. 377 CD cases and 349 ethnically matched controls were used in the initial screening, followed by an extended sample of 171 additional coeliac cases and 536 additional controls.

Results: Promotor SNPS $(-607,-137)$ in the IL18 gene, which has shown association with several autoimmune diseases, initially suggested association with CD ( $P<0.05)$. Follow-up analyses of an extended sample supported the same, moderate effect $(P<0.05)$ for one of these. Haplotype analysis of IL 18-137/-607 also supported this effect, primarily due to one relatively rare haplotype IL18-607C/-137C ( $<<0.0001)$, which was independently associated in two case-control comparisons. This same haplotype has been noted in rheumatoid arthritis.

Conclusion: Haplotypes of the IL18 promotor region may contribute to CD risk, consistent with this cytokine's role in maintaining inflammation in active CD.
\end{abstract}

\section{Background}

Coeliac disease (CD), or gluten intolerance is an autoimmune inflammatory condition of the small bowel, precipitated by gluten and related proteins from dietary grains such as wheat, barley and rye. Removal of these proteins from the diet is usually sufficient for complete remission of symptoms. The primary genetic determinant of $C D$ risk is inheritance of the HLA-DQ2 molecule, encoded by genes ( $H L A D Q A 1$ and $H L A D Q B 1)$ on chromosome $6 \mathrm{p} 21$. However, other genetic risk factors are known to

\footnotetext{
* Correspondence: aryan12@tcd.ie

1 Department of Clinical Medicine, Trinity Centre for Health Sciences, Trinity College Dublin, St James's Hospital, Dublin, Ireland

† Contributed equally

Full list of author information is available at the end of the article
}

exist, a number of which have been identified by linkage studies [1-3] or, more recently, whole genome SNP analyses $[4,5]$.

Several genomic regions thought to harbour susceptibility genes have been identified by family studies. Linkage of several of these regions to $C D$ has been replicated in independent studies from multiple populations. Of these, chromosomal regions 5q31 and 11q23 have been most successfully replicated. The linkage of 11q markers to coeliac disease have been demonstrated by 3 studies [1-3]. Markers from 115.8 Mb (D11S4111) to 123.6 (D11S4464) have shown linkage, with peak associations at D11S4142 at chromosome position $115.3 \mathrm{Mb}$ [2], and D11S4464 at $123.6 \mathrm{Mb}$ [3]. 
This region harbours several candidate genes for $C D$ susceptibility. Louka et al [6] reported no association between $\mathrm{CD}$ and functional polymorphisms in the MMP1 and MMP3 genes. However, Mora et al [7] reported a sex specific association between an MMP3 promotor polymorphism and coeliac disease.

The CD3 genes (118.2 Mb), CD3-epsilon (CD3E), CD3delta $(C D 3 D)$ and CD3-gamma (CD3G), lie within $50 \mathrm{~kb}$ of each other in this region, forming part of the T-cellreceptor (TCR) complex. This complex consists of either alpha and beta or gamma and delta variant chains, in association with the invariant chains $C D 3 E, C D 3 D$, $C D 3 G$ and $C D 3$-zeta (CD3Z). During development, this $C D 3$ protein complex plays an important role in the transition of thymocytes from immature precursors to the final mature CD4+ or CD8+ single-positive T-cell. Studies have shown that the $C D 3$ components are essential during the early stages of human thymopoiesis and deficiencies in these genes have been linked with severe combined immunodeficiency $[8,9]$. One preliminary study has been carried out to date on the association between $C D 3$ and autoimmune disease [10], which identified a significant association between $C D 3 D$ and type 1 diabetes with the use of microsatellites.

Also located on $11 \mathrm{q} 23$ is the THY1 gene $(119.2 \mathrm{Mb})$. This gene encodes a major cell surface glycoprotein characteristic of T-cells and is a member of the immunoglobulin supergene family. Although the role of this protein is not fully elucidated, its position as a cell surface molecule on T-cells and its involvement in cell-cell interactions [11] make it a candidate gene for coeliac disease pathogenesis.

The IL10RA gene $(117.9 \mathrm{Mb})$ encodes the interleukin 10 receptor-alpha chain of the IL-10 receptor complex. This molecule is the receptor for IL10, an anti-inflammatory cytokine produced by a subset of activated T-cells, B-cells and macrophages, which has a role in a variety of immunoregulatory functions [12]. Genetic variants of IL10RA have been shown to inhibit the production of TNF-alpha [13], a protein known to play a role in coeliac disease. Coeliac patients in remission produce significantly higher levels of TNFa than controls and while this appears to be a genetically inherited trait, it does not appear to be due solely to genetic variation at the TNF locus[14] [Daly and McManus, unpublished observation]. Thus, polymorphisms at other loci which could alter TNF production are high priorities for investigation as candidate genes.

A polymorphism in $I L 10(-1087)$ has been linked to a number of autoimmune diseases including inflammatory bowel disease, rheumatoid arthritis (RA) and systemic lupus erythematosus [15]. A significant association between the IL10-1087 polymorphism and coeliac disease has been shown [16]. However, this association failed to be replicated in subsequent work [17]. The IL101087 polymorphism has also been shown to be associated with differing levels of IgA anti-endomyseal and anti-tissue transglutaminase antibodies in CD patients [16], while recombinant human interleukin 10 has been shown to suppress gliadin dependent $\mathrm{T}$-cell activation in ex vivo cultured coeliac intestinal mucosa [18]. These observations suggest that ILIO may be a factor in the pathogenesis of CD. However, as IL10 signals through the specific receptor, ILIORA, a possible role for this receptor molecule in disease, mediated through the IL1O pathway, should also be considered. The strength of ILIORA as a candidate gene is enhanced by its physical proximity to D11S976, a microsatellite marker which has been highlighted in a number of family studies as showing linkage with CD.

Also present as a candidate gene in this region is $I L 18$ $(112.0 \mathrm{Mb})$, also known as interferon-gamma-inducing factor. Though this gene, located at chromosomal position 11q22.2-22.3, is some distance from the major linkage peaks in the region, it may still fall within the region of linkage as it is located between a marker shown to be linked to disease (D11S4111) at position 115.8 MB and the next tested marker (D11S898) at 101.0 MB which was not linked to disease [2]. IL18 is a proinflamatory cytokine which, in synergy with IL12, promotes development of the Th1 lymphocyte response by induction of $\gamma$ interferon (IFN- $\gamma$ ). The latter is highly produced in $\mathrm{CD}$ lesions, and is known to play an important role in inflammatory and infectious diseases [19]. Furthermore, increased serum levels of IL18 have been identified in patients with autoimmune diseases such as RA [20] and acute asthma [21]. Two polymorphisms in the promoter region of the gene have shown evidence of altering IL18 protein expression. One polymorphism located at position -607 has been found to disrupt a potential cAMPresponse element protein-binding site, while the other at position -137 alters a consensus H4TF-1 nuclear factorbinding site. Multiple sclerosis patients homozygous for the $-607 \mathrm{C}$ and $-137 \mathrm{G}$ alleles have higher levels of IL18 mRNA compared to other diplotypes, suggesting that these polymorphisms do indeed regulate activity of the gene [22]. More recent results point to a haplotypic effect based on other polymorphisms [23]. Numerous genetic association studies have been carried out on these SNPs and others in the gene, to investigate if any association exists with various autoimmune diseases. Significant association has been shown between IL18 and type 1 diabetes [24], Crohn's disease [25], atopic eczema [26], inflammatory bowel disease [27], and asthma [28]. Other studies have failed to find a disease association between IL18 and several diseases, among which are studies on coeliac disease [29], RA [30], type 1 diabetes [31-33], and periodontitis [34]. A recent study, which included analy- 
sis of the Irish samples analysed in this study, has identified functional genetic variants at IL18RAP, a receptor for IL18, as a risk factor in coeliac disease [35].

Here we report candidate gene analysis of the above genes, using a haplotype tagging approach to maximise coverage of the common genetic variants in European populations. In addition to the analyses performed for this study, we also tested for epistatic effects between IL18 and IL18RAP.

\section{Methods}

377 biopsy-confirmed unrelated coeliac patients and 349 controls were used as an initial screening population. All controls were healthy, randomly selected blood donors, and all case and control subjects were of uniform Irish ancestry. Sample characteristics are summarised in Table 1. Informed consent was obtained from all study subjects and the study was approved by the Ethics Committees of St James's Hospital, Dublin and the Mater Misericordiae University Hospital, Dublin. 10\% of samples were re-genotyped anonymously in order to evaluate error rates. SNPs with an uncorrected $\mathrm{P}$ value $<0.05$ on the initial screen were then tested on an additional sample of 171 coeliacs and 536 controls and the data pooled. Coeliac samples are biopsy proven, the significant majority (> $80 \%$ ) of which have the severe phenotype (Marsh III or greater) at the time of biopsy. In the absence of clear damage to the villous architecture, patients are diagnosed on the basis of an IEL infiltrate and or crypt hyperplasia (Marsh I/II) AND positivity for antibody tests (both antiEMA and anti-tTG) and where possible, evidence of clinical improvement on a gluten free diet. $H L A-D Q B 1$ testing of approximately 300 patients shows over $99 \%$ are positive for one or more of the known $H L A-D Q B 1$ alleles, HLA-DQB1"0201/0202/0301/0302.

In order to optimise genotyping efficiency, haplotype tags were identified for each gene. IL1ORA and IL18 haplotype tags were identified from complete, or near complete, phased re-sequence data from SeattleSNPs http:// pga.gs.washington.edu/education.html and Innate Immunityhttp://www.pharmgat.org/IIPGA2/index html databases. Re-sequence data were not available for the 3 CD3 genes or THY1. For these, genotype data were downloaded from the NCBI and Perlegen databases and gametic phase was assigned. Haplotype tags for each of the above genes were identified using the SNPtagger program, in order to tag common haplotypes (>5\%) for SNPs with minor allele frequency $>0.05$. Genotyping was performed using Amplifluor ${ }^{\text {ru }}$ or Taqman ${ }^{\text {tw }}$ technology. Tests for allele and haplotype frequency heterogeneity were performed using HITAGENE, GENEPOP[36], HAPLOSTATS[37] and PHASEv2 [38]. Tests for gene-gene interaction were performed using PLINK[39].

\section{Results}

All loci conformed to Hardy-Weinberg Equilibrium (P > 0.05) in all populations, with the exception of $C D 3 E$ rs1945764 in control population $1(\mathrm{P}=0.042)$. Anonymous genotype duplication suggested an error rate $<1 \%$. Patterns of linkage disequilibrium (LD) are presented in Supplementary Figure S1 (Additional File 1). All polymorphic sites in IL10RA, CD3D, CD3E, CD3G, THY1 and IL18 were analysed for allelic, genotypic and carrier status association with disease individually and results are summarised in Table 2. No polymorphism within the IL1ORA, CD3D, CD3E, CD3G or THY1 genes were found to be significantly associated with disease in this study. In the initial phase, two polymorphisms in the IL18 gene (IL18-137 rs187238 and IL18-607 rs1946518) showed a significant association with disease prior to correction for multiple testing. IL18-137 was significantly associated with disease (genotype frequency heterogeneity, $\mathrm{P}=$ 0.0380, Table 2). IL18-607 also showed a significant association with disease status (genotype frequency heterogeneity, $\mathrm{P}=0.005$; carrier status for the major allele, $\mathrm{P}=$ 0.001 , Odds Ratio $=1.955$ [CI, 1.30-2.95]).

These polymorphisms were further investigated in an augmented sample with 171 additional coeliacs and 536 random controls from the Irish Blood Transfusion Service (Table 2). These controls were compared with coeliacs separately and as a single pooled population, bringing the total number of control samples to 885 . Comparison of the pooled coeliac sample with pooled control samples suggested a moderate effect for IL18-607, though it was weaker than that observed for coeliac 1 Vs control 1 (Table 2). In addition, tests for epistasis using PLINK software did not suggest any interaction between these IL18 and IL18RAP genes in coeliac disease susceptibility.

Haplotype analysis (Table 3) of the IL18-607/-137 supported this moderate effect over all haplotypes $(\mathrm{P}<$

Table 1: Sample sizes, age and sex for cases and controls.

\begin{tabular}{lcccc}
\hline & N & \% Female & Age (mean) & SD \\
\hline Coeliac 1 & & & & \\
Coeliac 2 & 377 & 71 & 50.3 & 14.2 \\
Control 1 & 171 & 68 & 44.5 & 15.5 \\
Control 2 & 349 & 57 & 32.6 & 8.5 \\
\hline
\end{tabular}


Table 2: Comparison of genotypic frequencies (\%) between Coeliac and Control samples (Table 1) and the pooled Coeliac $(1+2)$ and Control $(1+2)$ samples.

\begin{tabular}{|c|c|c|c|c|c|}
\hline & & A1A1 & A1A2 & A2A2 & $\mathbf{p}$ \\
\hline \multicolumn{6}{|l|}{ Coeliac 1 Vs Control 1} \\
\hline IL10RA & Coeliac 1 & $86(23.1)$ & $192(51.8)$ & $93(25.1)$ & \\
\hline $\mathrm{rs} 2256111 \mathrm{~A} / \mathrm{G}$ & Control 1 & $69(19.8)$ & $192(55.0)$ & $88(25.2)$ & 0.514 \\
\hline IL10RA & Coeliac 1 & $255(68.0)$ & $101(26.9)$ & $19(5.1)$ & \\
\hline rs4252272 A/G & Control 1 & $226(64.8)$ & $115(33.0)$ & $8(2.3)$ & 0.068 \\
\hline IL10RA & Coeliac 1 & $171(45.4)$ & $169(44.8)$ & $37(9.8)$ & \\
\hline rs $2229113 \mathrm{G} / \mathrm{A}$ & Control 1 & $150(43.7)$ & $167(48.7)$ & $26(7.6)$ & 0.426 \\
\hline IL10RA & Coeliac 1 & $113(30.3)$ & $191(51.2)$ & $69(18.5)$ & \\
\hline rs9610 G/A & Control 1 & $96(28.0)$ & $184(53.6)$ & $63(18.4)$ & 0.767 \\
\hline CD3E & Coeliac 1 & $118(33.3)$ & $178(50.3)$ & $58(16.4)$ & \\
\hline rs3782042 G/A & Control 1 & $133(39.6)$ & $158(47.0)$ & $45(13.4)$ & 0.196 \\
\hline CD3E & Coeliac 1 & $158(49.7)$ & $131(41.2)$ & $29(9.1)$ & \\
\hline rs1945764 T/C & Control 1 & $155(45.9)$ & $160(47.3)$ & $23(6.8)$ & 0.223 \\
\hline CD3DG & Coeliac 1 & $193(54.4)$ & $137(38.6)$ & $25(7.0)$ & \\
\hline rs2276423 G/C & Control 1 & $171(49.9)$ & $142(41.4)$ & $30(8.8)$ & 0.434 \\
\hline CD3DG & Coeliac 1 & $240(66.5)$ & $109(30.2)$ & $12(3.3)$ & \\
\hline rs3181259 G/A & Control 1 & $238(69.6)$ & $97(28.4)$ & $7(2.1)$ & 0.469 \\
\hline CD3DG & Coeliac 1 & 147 (41.9) & $159(45.3)$ & $45(12.8)$ & \\
\hline rs1561966 G/A & Control 1 & $129(38.2)$ & $170(50.3)$ & $39(11.5)$ & 0.422 \\
\hline CD3DG & Coeliac 1 & $187(52.5)$ & $139(39.0)$ & $30(8.4)$ & \\
\hline rs7949185 T/C & Control 1 & $183(53.2)$ & $132(38.4)$ & $29(8.4)$ & 0.983 \\
\hline THY1 & Coeliac 1 & $161(43.5)$ & $171(46.2)$ & $38(10.3)$ & \\
\hline rs1894006 G/A & Control 1 & $161(47.1)$ & $155(45.3)$ & $26(7.6)$ & 0.380 \\
\hline THY1 & Coeliac 1 & $122(34.3)$ & $173(48.6)$ & $61(17.1)$ & \\
\hline rs1001205 G/A & Control 1 & $127(37.9)$ & $160(47.8)$ & $48(14.3)$ & 0.468 \\
\hline IL18 & Coeliac 1 & $145(44.2)$ & $147(44.8)$ & $36(11.0)$ & \\
\hline rs2043055 A/G & Control 1 & $116(38.2)$ & $156(51.3)$ & $32(10.5)$ & 0.244 \\
\hline IL18 & Coeliac 1 & $154(50.3)$ & $135(44.1)$ & $17(5.6)$ & \\
\hline * -137 rs $187238 \mathrm{G} / \mathrm{C}$ & Control 1 & $184(54.6)$ & $121(35.9)$ & $32(9.5)$ & 0.038 \\
\hline IL18 & Coeliac 1 & $227(75.7)$ & $68(22.7)$ & $5(1.7)$ & \\
\hline rs5744241 A/G & Control 1 & $237(82.3)$ & $49(17.0)$ & $2(0.7)$ & 0.114 \\
\hline IL18 & Coeliac 1 & $138(36.6)$ & $192(51.1)$ & $46(12.2)$ & \\
\hline${ }^{*}-607$ rs $1946518 \mathrm{C} / \mathrm{A}$ & Control 1 & $100(31.1)$ & $153(47.5)$ & $69(21.4)$ & 0.005 \\
\hline \multicolumn{6}{|l|}{ Coeliac 2 Vs Control 2} \\
\hline IL18 & Coeliac 2 & 99 (57.9) & $56(32.7)$ & $16(9.4)$ & \\
\hline-137 rs187238 G/C & Control 2 & $272(52.7)$ & $208(40.2)$ & $37(7.1)$ & 0.641 \\
\hline IL18 & Coeliac 2 & $50(42.4)$ & $48(40.7)$ & $20(16.9)$ & \\
\hline-607 rs1946518 C/A & Control 2 & $201(37.5)$ & $256(47.8)$ & $79(14.7)$ & 0.712 \\
\hline \multicolumn{6}{|c|}{ Coeliac $(1+2)$ Vs Controls $(1+2)$} \\
\hline IL18 & Coeliac & $253(53.0)$ & $191(40.0)$ & $33(6.9)$ & \\
\hline
\end{tabular}


Table 2: Comparison of genotypic frequencies (\%) between Coeliac and Control samples (Table 1) and the pooled Coeliac $(1+2)$ and Control $(1+2)$ samples. (Continued)

\begin{tabular}{|c|c|c|c|c|c|}
\hline-137 rs187238 G/C & Control & $456(53.4)$ & $329(38.5)$ & $69(8.1)$ & 0.696 \\
\hline IL18 & Coeliac & $188(38.1)$ & $240(48.6)$ & $66(13.4)$ & \\
\hline-607 rs1946518 C/A & Control & $301(35.1)$ & 409 (47.7) & $148(17.2)$ & 0.042 \\
\hline
\end{tabular}

Pvalues (uncorrected for multiple testing) are for genotype heterogeneity (GENEPOP). SNPs with a reportedly functional role are marked with an asterisk $(*)$.

$0.0001)$. This is primarily due to the $I L 18-607 C /-137 C$ haplotype, and the effect is detectable in the original case control comparison $(\mathrm{P}=0.00015$, coeliac 1 Vs control 1 , Table 3$)$, the follow up sample ( $\mathrm{P}=0.004$, coeliac $2 \mathrm{Vs}$ control 2, Table 3$)$, despite the limited size $(\mathrm{N}=171)$ of the coeliac 2 sample, and in the pooled case-control sample $(\mathrm{P}<0.00001$, Table 3$)$. Furthermore, the values presented are corrected for the confounding effects of age and sex. The P-values obtained for haplotype analysis are presented without correction for multiple testing, but the global tests (case-control $1, \mathrm{P}=0.00075$; case control 2, $\mathrm{P}$ $=0.0059$; pooled case-control $\mathrm{P}<0.00001$ ) are significant after correction for multiple testing across 6 gene regions.

\section{Discussion}

This candidate gene investigation of the chromosome 11 coeliac disease linkage region, which has been identified by several linkage studies [1-3], contains analysis of six genes; CD3E, CD3D, CD3G, IL1ORA, THY1 and IL18. Haplotype tagging strategies were used to define haplotypes around the genes of interest, ensuring the maximum information content is gained. Polymorphisms previously shown to be associated with disease or those with a theoretical or proven functional role (e.g. gene promoter regulation or transcription factor binding site alteration) have been included where possible in this study to provide as comprehensive a picture as possible of the genetic variation present in these genes.

Table 3: Haplotype frequencies in Coeliacs and Controls.

\begin{tabular}{|c|c|c|c|c|c|c|c|}
\hline IL18-607 & IL18-137 & *Coeliac & *Control & Hap-Freq & Hap-Score & p-val & sim p-val \\
\hline \multicolumn{8}{|c|}{ Coeliac 1 Vs Control 1} \\
\hline A & $\mathrm{C}$ & 0.251 & 0.284 & 0.277 & -0.717 & 0.473 & 0.467 \\
\hline A & G & 0.136 & 0.156 & 0.138 & -0.776 & 0.443 & 0.438 \\
\hline C & G & 0.591 & 0.558 & 0.571 & 0.161 & 0.872 & 0.867 \\
\hline C & $\mathrm{C}$ & 0.022 & 0.002 & 0.014 & 4.056 & 0.00005 & 0.00015 \\
\hline \multicolumn{8}{|c|}{ Coeliac 2 Vs Control 2} \\
\hline A & $\mathrm{C}$ & 0.173 & 0.269 & 0.264 & -1.231 & 0.218 & 0.241 \\
\hline A & G & 0.164 & 0.127 & 0.129 & 1.162 & 0.245 & 0.241 \\
\hline C & $\mathrm{C}$ & 0.072 & 0.007 & 0.009 & 3.139 & 0.002 & 0.004 \\
\hline \multicolumn{8}{|c|}{ Coeliac $(1+2)$ Vs Control $(1+2)$} \\
\hline A & $C$ & 0.234 & 0.275 & 0.271 & -0.909 & 0.364 & 0.364 \\
\hline$A$ & $\mathrm{G}$ & 0.142 & 0.138 & 0.134 & 0.577 & 0.564 & 0.566 \\
\hline C & G & 0.591 & 0.582 & 0.584 & -0.630 & 0.529 & 0.531 \\
\hline $\mathrm{C}$ & $\mathrm{C}$ & 0.032 & 0.005 & 0.012 & 4.956 & 0.00001 & 0.00001 \\
\hline
\end{tabular}

Case and Control haplotype frequencies were calculated using PHASE v2*. All other calculations were performed using HAPLOSTATS, and corrected for the effects of age and sex. P values are presented without correction for multiple testing. Haplotype IL 18-607C/-137C is rare but confers risk (highly significant). Case 1 Vs Control 1, HAPLOSTATS global-stat $=16.880, d f=3, P<0.00075$. The same effect is evident when comparing coeliac 2 to control cohort 2, HAPLOSTATS global-stat $=12.49, \mathrm{df}=3, \mathrm{P}=0.0059$. For comparison of pooled cases $(1+2) \mathrm{Vs}$ pooled controls $(1+2)$, HAPLOSTATS global-stat $=25.620, \mathrm{df}=3, \mathrm{P}<0.00001$, PHASE v2, overall $\mathrm{P}=0.01, \mathrm{HITAGENE}, \mathrm{P}<0.05$. 
Patterns of LD (Supplementary Figure S1, Additional file 1) were generally consistent with those seen in the CEPH European individuals in the Hapmap data, suggesting the genes in question have been effectively tagged. Linkage disequilibrium analysis of the 11q23 region showed that SNPs within each gene showed evidence of LD with other SNPs in the same gene. However, there was little to no inter-gene LD present, except in the $C D 3$ gene cluster. Thus the haplotype structure of each gene was assessed separately for association with disease.

The promoter polymorphisms in IL18 were initially found to be associated with $\mathrm{CD}$, before correction for multiple testing. Analysis of follow-up samples suggested that this first finding may be due to a haplotypic effect. This is primarily due to the $I L 18-607 C /-137 C$ haplotype, and the effect is detectable in the original case control comparison, the follow up sample (despite the limited size [ $\mathrm{N}=171]$ of the coeliac 2 sample) and in the pooled case-control sample. Furthermore, the values presented are corrected for the confounding effects of age and sex, and remain significant when considering the effects of multiple testing.

Candidate gene studies may yield conflicting results, which may be due to population stratification, sampling bias, inadequate sample size, variation in study design, and mis-classification of phenotypes [40-42]. Population stratification and sampling bias are unlikely to be an issue, as all cases and controls were unrelated individuals of ethnically uniform Irish origin. Power calculations [43] indicate that our sample sizes afforded $>80 \%$ power to detect an effect of genotype relative risk 1.3 for heterozygotes and 1.6 for homozygotes for a range of allele frequencies. While the effect size for IL18-607 was higher in the first samples (coeliac $1 \mathrm{Vs}$ control 1, genotype relative risk 1.36 for heterozygotes and 1.84 for homozygotes), the same comparison in the second (much smaller) set of samples was not statistically significant. The combined dataset was consistent with a weak effect for IL18-607 (genotype relative risk 1.16 for heterozygotes and 1.33 for homozygotes). However, a much greater effect was observed at the haplotype level, in both case-control sample sets independently and in the combined sample. Using PLINK, we estimate the effect size of the IL18-607C/ $-137 \mathrm{C}$ haplotype in our combined case-control sample to have an odds ratio $=6.2$; thus although rare, it is associated with a relatively large risk. Power calculations using haplo.power.cc (HAPLOSTATS) suggest that our sample sizes afford $>95 \%$ power to detect a haplotypic effect of odds ratio 3 or greater at the $5 \%$ level in both our casecontrol samples, and the combined sample, consistent with our observation of this effect in all three comparisons.

A previous study based on the TDT analysis [29] has examined the relationship between IL18 and CD by examination of these two promoter polymorphisms in 105 Spanish families, and found no association with disease. The differences between their result and ours may reflect differences in study design and the rarity of the IL18-137C/-607C haplotype, the frequency of which is unknown in Spain. It was not reported by Rueda et al [29] for the Spanish population, but the control frequencies observed by us are similar to those reported for the German and Scottish populations [44].

Four of the 16 SNPs used in this study have been included in a genome-wide analysis of coeliac disease risk [4], where none showed association with disease. While that study did include analysis of IL18-607 (rs1946518), IL18-137 (rs187238) was not analysed. The haplotype found in this study would not, therefore, have been detected.

Interestingly, follow-up of the top 1500 positive results from coeliac disease whole genome analysis [4] has provided robust replication of association with 7 loci, all of which have a clear functional role in T-cell regulation [35]. Furthermore, based on these findings it has been calculated that non-HLA loci identified to-date contribute approximately $4 \%$ to the total CD risk, although this may be an underestimate. Meanwhile, the contribution of HLA-DQ2 and -DQ8 has been calculated at 35\% [35]. Therefore, it is apparent that additional factors remain to be discovered. While much of this missing heritability may relate to low risk variants, it is likely that much of the remaining variation may not be well detected by association of single SNPs in the absence of reference to haplotypes.

The observations that all the newly identified risk variants are associated with genes with a known role in a relevant pathway, and that additional risk variants remain to be uncovered, are highly pertinent in the context of directed candidate gene analyses. This approach can be applied to regions of known linkage to disease, and can be focused on pathways (e.g T-cell regulation) that are known to be important in the aetiology of the disease. It is of particular interest that one highly replicated nonHLA CD risk modulator, the CTLA4 locus on chromosome $2 q 33[45,46]$ was not detected in linkage studies or the initial genome wide assocation study, although it has since been significantly associated in a large combined type 1 diabetes/coeliac disease study [47]

\section{Conclusions}

Our results suggest a possible haplotypic association between SNPs in the IL18 locus and coeliac disease risk. While this may represent a chance statistical departure rather than a true disease association, the same relatively rare haplotype has been noted in two independent rheumatoid arthritis populations [44]. Furthermore, the role of ILI8 as a CD candidate gene is further strengthened by 
evidence to suggest that it plays a key role in the maintenance of inflammation in active CD [48]. Directed candidate gene analyses, in combination with more indepth analysis of haplotypic variation may still contribute to our knowledge of complex disease risk, as many relevant effects remain undetected. The $5 \mathrm{q}$ and $11 \mathrm{q}$ linkage regions contain numerous un-investigated immunerelated genes, many of which are plausible candidate genes for CD risk. These may form part of the next phase of candidate gene studies in this condition.

\section{Additional material}

Additional file 1 Supplementary Figure S1. Linkage Disequilibrium (D')

in the 11q23 region in coeliac cases (a) and controls (b).

\section{Abbreviations}

CD: coeliac disease; CD3: CD3 antigen; EMA: anti-endomysial antibodies; H4TF1: H4 gene transcription factor; HLA: human leukocyte antigen; IEL: intraepithelial lymphocytes; IgA: immunoglobulin A; IL10: interleukin 10; IL10RA interleukin 10 receptor A; IL12: interleukin 12; IL18: interleukin 18; IL18RAP; interleukin 18 receptor accessory protein; RA: rheumatoid arthritis; SNP: single nucleotide polymorphism; TDT: Transmission Disequilibrium Test; THY1 (CD90): Thy-1 cell surface antigen; TNFa: tumour necrosis factor alpha; tTG: tissue transglutaminase.

\section{Competing interests}

The authors declare that they have no competing interests.

\section{Authors' contributions}

$K B, A W R$ and RMM designed the study, performed the statistical analysis and drafted the manuscript. KB, AWR, GT and KDP managed sample handling and performed DNA extraction and genotyping. MA, COM, NPK, VT, BE, EC, GL, PMM, FMS, CF and DK evaluated and recruited patients from several centres in Ireland. All authors have read and approved the final manuscript.

\section{Acknowledgements}

The authors acknowledge the funding provided by the Irish Health Research Board and Science Foundation Ireland, and thank both cases and controls for the provision of samples.

\section{Author Details}

'Department of Clinical Medicine, Trinity Centre for Health Sciences, Trinity College Dublin, St James's Hospital, Dublin, Ireland, 2Institute of Molecular Medicine, Trinity Centre for Health Sciences, St James's Hospital, Dublin, Ireland , 'BDepartment of Immunology, Trinity College, Trinity Centre for Health Sciences, St James's Hospital, Dublin, Ireland, ${ }^{4}$ Department of Clinical Medicine, Trinity College, Trinity Centre for Health Sciences, The Adelaide \& Meath Hospital Dublin, Incorporating The National Children's Hospital, Tallaght, Dublin, Ireland, ${ }^{5}$ Gastrointestinal Unit, Mater Misericordiae University Hospital, Dublin, Ireland, ${ }^{6}$ Department of Medicine, National University of Ireland, Galway, Ireland and 'Department of Immunology, Hull Royal Infirmary, Hull, UK

Received: 26 June 2009 Accepted: 17 May 2010

Published: 17 May 2010

\section{References}

1. Greco L, Corazza G, Babron MC, Clot F, Fulchignoni-Lataud MC, Percopo S, Zavattari P, Bouguerra F, Dib C, Tosi R, et al:: Genome search in celiac disease. Am J Hum Genet 1998, 62(3):669-675.

2. Holopainen P, Mustalahti K, Uimari P, Collin P, Maki M, Partanen J: Candidate gene regions and genetic heterogeneity in gluten sensitivity. Gut 2001, 48(5):696-701.

3. Naluai AT, Nilsson S, Gudjonsdottir AH, Louka AS, Ascher H, Ek J, Hallberg B, Samuelsson L, Kristiansson B, Martinsson T, et al:: Genome-wide linkage analysis of Scandinavian affected sib-pairs supports presence of susceptibility loci for celiac disease on chromosomes 5 and 11. Eur J Hum Genet 2001, 9(12):938-944.

4. van Heel DA, Franke L, Hunt KA, Gwilliam R, Zhernakova A, Inouye M, Wapenaar MC, Barnardo MC, Bethel G, Holmes GK, et al: A genome-wide association study for celiac disease identifies risk variants in the region harboring IL2 and IL21. Nat Genet 2007, 39(7):827-829.

5. Dubois PC, Trynka G, Franke L, Hunt KA, Romanos J, Curtotti A, Zhernakova A, Heap GA, Adany R, Aromaa A, et al: Multiple common variants for celiac disease influencing immune gene expression. Nat Genet 2010, 42(4):295-302

6. Louka AS, Stensby EK, Ek J, Gudjonsdottir AH, Ascher H, Sollid LM: Coeliac disease candidate genes: no association with functional polymorphisms in matrix metalloproteinase 1 and 3 gene promoters. Scand J Gastroenterol 2002, 37(8):931-935.

7. Mora B, Bonamico M, Ferri M, Megiorni F, Osborn J, Pizzuti A, Mazzilli MC: Association of the matrix metalloproteinase-3 (MMP-3) promoter polymorphism with celiac disease in male subjects. Hum Immunol 2005, 66(6):716-720.

8. Dadi HK, Simon AJ, Roifman CM: Effect of CD3delta deficiency on maturation of alpha/beta and gamma/delta T-cell lineages in severe combined immunodeficiency. N Eng/ J Med 2003, 349(19):1821-1828.

9. de Saint G Basile, Geissmann F, Flori E, Uring-Lambert B, Soudais C, Cavazzana-Calvo M, Durandy A, Jabado N, Fischer A, Le Deist F: Severe combined immunodeficiency caused by deficiency in either the delta or the epsilon subunit of CD3. J Clin Invest 2004, 114(10):1512-1517.

10. Ghabanbasani MZ, Buyse I, Legius E, Decorte R, Marynen P, Bouillon R, Cassiman JJ: Possible association of CD3 and CD4 polymorphisms with insulin-dependent diabetes mellitus (IDDM). Clin Exp Immunol 1994, 97(3):517-521.

11. Rege TA, Hagood JS: Thy-1, a versatile modulator of signaling affecting cellular adhesion, proliferation, survival, and cytokine/growth factor responses. Biochim Biophys Acta 2006, 1763(10):991-999.

12. Moore KW, de Waal R Malefyt, Coffman RL, O'Garra A: Interleukin-10 and the interleukin-10 receptor. Annu Rev Immunol 2001, 19:683-765.

13. Gasche C, Grundtner P, Zwirn P, Reinisch W, Shaw SH, Zdanov A, Sarma U, Williams LM, Foxwell BM, Gangl A: Novel variants of the IL-10 receptor 1 affect inhibition of monocyte TNF-alpha production. J Immunol 2003, 170(11):5578-5582.

14. Daly JS, McManus R, Farrell R, Weir DG, Kelleher D: Tumour necrosis factor-a production significantly increased in coeliac disease is not associated with the TNFa2 microsatellite polymorphism. Immunology Letters 1997, 56(1):40-41

15. Turner DM, Williams DM, Sankaran D, Lazarus M, Sinnott PJ, Hutchinson IV: An investigation of polymorphism in the interleukin-10 gene promoter. Eur J Immunogenet 1997, 24(1):1-8,

16. Hahn-Zoric M, Hytonen AM, Hanson LA, Nilsson LA, Padyukov L: Association of -1087 IL10 and -308 TNFA gene polymorphisms with serological markers of coeliac disease. J Clin Immunol 2003, 23(4):291-296.

17. Lio D, Scola L, Forte Gl, Accomando S, Giacalone A, Crivello A, Cataldo F: TNFalpha, IFNgamma and IL-10 gene polymorphisms in a sample of Sicilian patients with coeliac disease. Dig Liver Dis 2005, 37(10):756-760.

18. Salvati VM, Mazzarella G, Gianfrani C, Levings MK, Stefanile R, De Giulio B, laquinto G, Giardullo N, Auricchio S, Roncarolo MG, et al:: Recombinant human interleukin 10 suppresses gliadin dependent $T$ cell activation in ex vivo cultured coeliac intestinal mucosa. Gut 2005, 54(1):46-53.

19. McInnes IB, Gracie JA, Leung BP, Wei XQ, Liew FY: Interleukin 18: a pleiotropic participant in chronic inflammation. Immunol Today 2000, 21(7):312-315.

20. Gracie JA, Forsey RJ, Chan WL, Gilmour A, Leung BP, Greer MR, Kennedy K, Carter R, Wei XQ, Xu D, et al:: A proinflammatory role for IL-18 in rheumatoid arthritis. J Clin Invest 1999, 104(10):1393-1401.

21. Tanaka H, Miyazaki N, Oashi K, Teramoto S, Shiratori M, Hashimoto M, Ohmichi M, Abe S: IL-18 might reflect disease activity in mild and moderate asthma exacerbation. J Allergy Clin Immunol 2001, 107(2):331-336

22. Giedraitis V, He B, Huang WX, Hillert J: Cloning and mutation analysis of the human IL-18 promoter: a possible role of polymorphisms in expression regulation. J Neuroimmuno/ 2001, 112(1-2):146-152.

23. Barbaux S, Poirier O, Godefroy T, Kleinert H, Blankenberg S, Cambien F, Tiret L: Differential haplotypic expression of the interleukin-18 gene. Eur J Hum Genet 2007, 15(8):856-863. 
24. Kretowski A, Mironczuk K, Karpinska A, Bojaryn U, Kinalski M, Puchalski Z, Kinalska I: Interleukin-18 promoter polymorphisms in type 1 diabetes. Diabetes 2002, 51(11):3347-3349.

25. Tamura K, Fukuda Y, Sashio H, Takeda N, Bamba H, Kosaka T, Fukui S, Sawada K, Satomi M, Yamada T, et al.: IL18 polymorphism is associated with an increased risk of Crohn's disease. J Gastroenterol 2002, 37(Suppl 14):111-116.

26. Novak N, Kruse S, Potreck J, Maintz L, Jenneck C, Weidinger S, Fimmers R, Bieber T: Single nucleotide polymorphisms of the IL18 gene are associated with atopic eczema. J Allergy Clin Immunol 2005, 115(4):828-833.

27. Aizawa Y, Sutoh S, Matsuoka M, Negishi M, Torii A, Miyakawa Y, Sugisaka H, Nakamura M, Toda G: Association of interleukin-18 gene singlenucleotide polymorphisms with susceptibility to inflammatory bowel disease. Tissue Antigens 2005, 65(1):88-92.

28. Higa S, Hirano T, Mayumi M, Hiraoka M, Ohshima Y, Nambu M, Yamaguchi E, Hizawa N, Kondo N, Matsui E, et al:: Association between interleukin18 gene polymorphism 105A/C and asthma. Clin Exp Allergy 2003, 33(8):1097-1102.

29. Rueda B, Zhernakova A, Lopez-Nevot MA, Martin J, Koeleman BP: Association study of functional genetic variants of innate immunity related genes in celiac disease. BMC Med Genet 2005, 6:29.

30. Rueda B, Gonzalez-Gay MA, Mataran L, Lopez-Nevot MA, Martin J: Interleukin-18-promoter polymorphisms are not relevant in rheumatoid arthritis. Tissue Antigens 2005, 65(6):544-548.

31. Novota P, Kolostova K, Pinterova D, Novak J, Treslova L, Andel M, Cerna M: Interleukin IL-18 gene promoter polymorphisms in adult patients with type 1 diabetes mellitus and latent autoimmune diabetes in adults. Immunol Lett 2005, 96(2):247-251.

32. Ide A, Kawasaki E, Abiru N, Sun F, Fukushima T, Ishii R, Takahashi R, Kuwahara H, Fujita N, Kita A, et al:: Association of interleukin-18 gene promoter polymorphisms in type 1 diabetes and autoimmune thyroid disease. Ann N Y Acad Sci 2003, 1005:436-439.

33. Martin RJ, Savage DA, Carson DJ, Maxwell AP, Patterson CC: Interleukin 18 promoter polymorphisms are not strongly associated with type I diabetes in a UK population. Genes Immun 2005, 6(2):171-174.

34. Folwaczny M, Glas J, Torok HP, Tonenchi L, Paschos E, Bauer B, Limbersky $\mathrm{O}$, Folwaczny C: Polymorphisms of the interleukin-18 gene in periodontitis patients. J Clin Periodontol 2005, 32(5):530-534

35. Hunt KA, Zhernakova A, Turner G, Heap GA, Franke L, Bruinenberg M, Romanos J, Dinesen LC, Ryan AW, Panesar D, et al:: Newly identified genetic risk variants for celiac disease related to the immune response. Nat Genet 2008, 40(4):395-402.

36. Raymond M, Rousset F: GENEPOP (version 1.2): population genetics software for exact tests and ecumenicism. J Heredity 1995, 86:248-249.

37. Schaid DJ, Rowland CM, Tines DE, Jacobson RM, Poland GA: Score tests for association between traits and haplotypes when linkage phase is ambiguous. Am J Hum Genet 2002, 70(2):425-434.

38. Stephens M, Smith NJ, Donnelly P: A new statistical method for haplotype reconstruction from population data. Am J Hum Genet 2001, 68(4):978-989.

39. Purcell S, Neale B, Todd-Brown K, Thomas L, Ferreira MA, Bender D, Maller J, Sklar P, de Bakker PI, Daly MJ, et al.: PLINK: a tool set for whole-genome association and population-based linkage analyses. Am J Hum Genet 2007, 81(3):559-575.

40. Cardon LR, Palmer $L J$ : Population stratification and spurious allelic association. Lancet 2003, 361(9357):598-604.

41. Colhoun HM, McKeigue PM, Davey G Smith: Problems of reporting genetic associations with complex outcomes. Lancet 2003, 361(9360):865-872.

42. Tabor HK, Risch NJ, Myers RM: Candidate-gene approaches for studying complex genetic traits: practical considerations. Nat Rev Genet 2002, 3(5):391-397

43. Purcell S, Cherny SS, Sham PC: Genetic Power Calculator: design of linkage and association genetic mapping studies of complex traits. Bioinformatics 2003, 19(1):149-150.

44. Gracie JA, Koyama N, Murdoch J, Field M, McGarry F, Crilly A, Schobel A, Madhok R, Pons-Kuhnemann J, McInnes IB, et al:: Disease association of two distinct interleukin-18 promoter polymorphisms in Caucasian rheumatoid arthritis patients. Genes Immun 2005, 6(3):211-216.

45. Brophy K, Ryan AW, Thornton JM, Abuzakouk M, Fitzgerald AP, McLoughlin RM, O'Morain C, Kennedy NP, Stevens FM, Feighery C, et al:
Haplotypes in the CTLA4 region are associated with coeliac disease in the Irish population. Genes Immun 2006, 7(1):19-26.

46. Djilali-Saiah I, Schmitz J, Harfouch-Hammoud E, Mougenot JF, Bach JF, Caillat-Zucman S: CTLA-4 gene polymorphism is associated with predisposition to coeliac disease. Gut 1998, 43(2):187-189.

47. Smyth DJ, Plagnol V, Walker NM, Cooper JD, Downes K, Yang JH, Howson JM, Stevens H, McManus R, Wijmenga C, et al:: Shared and distinct genetic variants in type 1 diabetes and celiac disease. NEngl J Med 2008, 359(26):2767-2777.

48. Leon AJ, Garrote JA, Blanco-Quiros A, Calvo C, Fernandez-Salazar L, Del Villar A, Barrera A, Arranz E: Interleukin 18 maintains a long-standing inflammation in coeliac disease patients. Clin Exp /mmunol 2006 146(3):479-485

\section{Pre-publication history}

The pre-publication history for this paper can be accessed here: http://www.biomedcentral.com/1471-2350/11/76/prepub

doi: 10.1186/1471-2350-11-76

Cite this article as: Brophy et al., Evaluation of 6 candidate genes on chromosome 11 q23 for coeliac disease susceptibility: a case control study BMC Medical Genetics 2010, 11:76

\section{Submit your next manuscript to BioMed Central and take full advantage of:}

- Convenient online submission

- Thorough peer review

- No space constraints or color figure charges

- Immediate publication on acceptance

- Inclusion in PubMed, CAS, Scopus and Google Scholar

- Research which is freely available for redistribution

Submit your manuscript at www.biomedcentral.com/submit
C Biomed Central 